\title{
The influence on abdominal adhesions and inflammation in rabbits after exposure to differently charged polypeptides
}

\author{
Daniel Åkerberg, Carl Grunditz, Monika Posaric-Bauden, Karolin Isaksson, Roland Andersson, \\ Bobby Tingstedt*
}

Department of Surgery, Clinical Sciences, Skåne University Hospital, Lund, Sweden

Email: *bobby.tingstedt@med.lu.se

Received 4 May 2012; revised 12 June 2012; accepted 28 June 2012

\section{ABSTRACT}

Background: Abdominal adhesions develop on damaged peritoneal surfaces and constitute a significant health related problem. Previous animal studies have shown promising anti-adhesive effects when administering the polycation $\alpha$-poly-L-lysine $(\alpha \mathrm{PL})$ and the polyanion poly-L-glutamate (PG) together. The objective of the study was to examine the effect of these differently charged polypeptides when administered by spraying and to evaluate any possible effect on fibrinolysis, fibrosis and inflammation. Methods: Rabbits were treated with PLPG after cecal abrasive surgery and analysis from peritoneal biopsies of active tPa/PAI-1 complex and from peritoneal fluid of IL-6 and active TGFb1 at day $0,1,4$ and 10 were measured after surgery. Histological specimens were analyzed on day 10 regarding inflammation and fibrosis. Peritoneal adhesions were evaluated by adhesion score. All values were compared to the control group (NaCl). Results: PLPG-treated rabbits had a significant diminished adhesion score on day 10 as compared to the control group $(p<0.005)$. Significantly reduced collagen depositions on the peritoneum were seen in the PLPG group when evaluating the histological specimens $(p<0.05)$. No significant differences between the experimental and control groups were seen in peritoneal fluid when analyzing for active protein levels. Conclusion: This is the first study to investigate the effect on key parameters in adhesion formation as well as the preventive effect of the PLPG complex on abdominal adhesions in rabbits and also the first study where administration by spraying the polypeptides was used. PLPG was nontoxic in this setting and without significant differences in adhesion formation parameters and a significant reduction in adhesions was observed. This was verified both macroscopically and histologically.

*Corresponding author.
Keywords: Polycations; Abdominal Adhesions; Coagulation; Fibrosis; Inflammation

\section{INTRODUCTION}

Abdominal adhesions constitute a major clinical challenge causing small bowel obstruction [SBO], abdominal pain, female infertility and a high annual cost for healthcare [1,2]. Abdominal adhesions form due to surgery, abdominal infections, foreign bodies and other similar events that may harm the peritoneum $[3,4]$. The exact mechanism how adhesions form is not elucidated, but the overall picture is quite clear.

Remnants of fibrin due to impaired local fibrinolysis are considered to be the major initiator of abdominal adhesion development [5]. The fibrin residues may result in stable fibrin strands that become invaded by different inflammatory cells and collagen fibers, thus eventually forming stable adhesions [6-8]. Decreased tissue plasminogen activator (tPA) and elevated levels of plasminogen activator inhibitor-1 (PAI-1) resulting in diminished fibrinolysis along with extended fibrosis associated with increased transforming growth factor beta (TGF-b) and higher amounts of inflammatory cytokines such as IL1-6 are all part of the local peritoneal adhesion formation [9-11].

Previous in vivo studies (mouse and rat) have shown promising results when differently charged polypeptides, i.e., the polycation $\alpha$-poly-L-lysine and the polyanion $\alpha$-poly-L-glutamate, were combined together. They form a neutrally charged complex on the injured peritoneal site, thereby reducing adhesion formation [12].

This study aimed to investigate the anti-adhesive effect of the $\alpha$-poly-L-lysine and $\alpha$-poly-L-glutamate complex in a rabbit model and its possible effect on local peritoneal adhesion formation by measuring the active tPa/PAI-1 complex, TGFb1 and IL-6. To minimize the used dose, we aimed to examine whether administration by spraying the differently charged polypeptides decreased adhesions. Furthermore, we aimed to examine if 
the histological picture (inflammation and fibrosis) was influenced when administering the polymer complex on the peritoneal wound site.

\section{METHODS AND ANIMALS}

\subsection{Animals}

A total of 28 female Rabbits (Swedish Lop) weighing approximately $2.6-3.3 \mathrm{~kg}$ were used for induction of peritoneal adhesions. The animals were kept under standardized conditions and had free access to water and pellets. The local ethical committee at Lund University approved the adhesion study (Lund, Sweden M39-10) and the animals received the best animal care in compliance with the guidelines of the Swedish Government and Lund University, Sweden.

\subsection{Chemicals}

The chemicals $\alpha$-poly-L-lysine MW > 30,000 kDa (PL) and $\alpha$-poly-L-glutamate MW 15 - 50 kD (PG) (Sigma Aldrich $^{\mathrm{TM}}$, St. Louis, Missouri, USA) were freshly mixed on the day of the experiment with $2.54 \%$ glycerol and water in an osmotic balanced solution to a final concentration of $0.5 \%(5 \mathrm{mg} / \mathrm{ml})$. They were put in separate bottle atomizers that administrated $0.5 \mathrm{ml}$ volume with one dose.

\subsection{Model}

The animals were anesthetized with $50 \mathrm{mg} / \mathrm{kg}$ Ketalar (Parker Davis ${ }^{\mathrm{TM}}$ Detroit, Michigan, USA) and Xylazine $6 \mathrm{mg} / \mathrm{kg}$ (Rompun: Bayer Sverige AB Sweden) by an intramuscular injection.

A standardized animal adhesion model, cecal abrasion, was performed under sterile conditions. In brief, after a $10 \mathrm{~cm}$ midline incision, the cecal area (approx. $2 \mathrm{~cm}^{2}$ ) was abraded to petechial bleeding using a dry sponge. On the right side of the abdominal wall a square section of $1 \mathrm{~cm} \times 1 \mathrm{~cm}$ peritoneum was excised down to the right transverse abdominal muscle and the wound surfaces were gently dabbed with sterile gauze to remove excess blood. The abraded cecum was put back into the abdomen adjacent to the denuded lateral wall.

Treatment was then applied by first spraying the PL and thereafter PG followed by abdominal closure using a running suture (Prolene ${ }^{\mathrm{TM}}$ 4-0, Ethicon, Somerville, NJ, USA) in two layers. The animals received subcutaneous saline $(0.9 \%, 10 \mathrm{ml})$ for resuscitation and buprenorphine for postoperative pain control.

All animals were weighed in conjunction with every operative procedure.

\subsection{Experimental Design}

The rabbits were randomly and blinded divided at the beginning of the experiment into different groups according to Table 1. Group A $(n=6)$ received a dose of PL and PG $(0.5 \%, 1 \mathrm{ml}$ of each corresponding to a dose of $2 \mathrm{mg} / \mathrm{kg}$ ) administered by spray; first the PL was sprayed and after 10 - 15 seconds the PG was given. The control group B $(n=6)$ received saline $(0.9 \%) 2 \mathrm{ml}$ administered locally by spraying after the surgical procedure but before closure of the abdomen.

In groups $\mathrm{A}$ and $\mathrm{B}$ peritoneal lavage and biopsies of tissue (size $1-2 \mathrm{~mm}^{2}$ ) in the operation area of the abdominal wall were taken on day 0 (prior to surgery) and days 1,4 and 10 postoperatively on repeated laparotomies. Biopsies were taken from new areas of the operated area on each occasion. Lavage containing $37^{\circ} \mathrm{C} 20$ $\mathrm{ml}$ Phosphate Buffered Saline $3 \mathrm{mM}$ EDTA and $25 \mathrm{U} / \mathrm{ml}$ Heparin (LEO Pharma AB ${ }^{\mathrm{TM}}$ Malmö, Sweden) was collected in tubes by (Becton Dickingson ${ }^{\mathrm{TM}}$, San Jose, California, USA) and immediately centrifuged at $1000 \mathrm{G}$ for $4 \mathrm{~min}$ at $4^{\circ} \mathrm{C}$. The supernatant was allocated and snap frozen up to $-80^{\circ} \mathrm{C}$. Peritoneal biopsies were homogenized in $\mathrm{NaH}_{2} \mathrm{PO}_{4}$ buffer containing $0.1 \%$ Triton X 100 (Sigma Aldrich $^{\mathrm{TM}}$ St. Louis, Missouri, USA) and thereafter centrifuged at $1000 \mathrm{G}$ for 10 minutes at $4^{\circ} \mathrm{C}$. Additional peritoneal biopsies from the same area were taken on day 10 in order to stain for inflammatory cells (Hematoxylin and Eosin) and collagen (Massons-Trichrome). Prior to staining, the biopsies were treated with acetaldehyde, fixated in alcohol, paraffin embedded and cut with a microtome.

Group C $(\mathrm{n}=8)$ received PL and PG in the same dose and mode as group A $(0.5 \%, 1 \mathrm{ml}$ of each corresponding to a dose of $2 \mathrm{mg} / \mathrm{kg})$ and group $\mathrm{D}(\mathrm{n}=8)$ received saline $(0.9 \%, 2 \mathrm{ml})$ after the abrasion procedure (described above).

Ten days later the macroscopic peritoneal adhesions in group $\mathrm{C}$ and $\mathrm{D}$ were noted and carefully dissected. The

Table 1. Experimental design.

\begin{tabular}{|c|c|c|c|c|c|}
\hline Group & Animals & Day 0 & Day 1 & Day 4 & Day 10 \\
\hline A & 6 & $\begin{array}{l}\text { Peritoneal } \\
\text { lavage, } \\
\text { Peritoneal } \\
\text { biopsy }\end{array}$ & $\begin{array}{l}\text { Peritoneal } \\
\text { lavage, } \\
\text { Peritoneal } \\
\text { biopsy }\end{array}$ & $\begin{array}{l}\text { Peritoneal } \\
\text { lavage, } \\
\text { Peritoneal } \\
\text { biopsy }\end{array}$ & $\begin{array}{l}\text { Peritoneal } \\
\text { lavage, } \\
\text { Peritoneal } \\
\text { biopsy, } \\
\text { Histology }\end{array}$ \\
\hline B & 6 & $\begin{array}{l}\text { Peritoneal } \\
\text { lavage, } \\
\text { Peritoneal } \\
\text { biopsy }\end{array}$ & $\begin{array}{l}\text { Peritoneal } \\
\text { lavage, } \\
\text { Peritoneal } \\
\text { biopsy }\end{array}$ & $\begin{array}{l}\text { Peritoneal } \\
\text { lavage, } \\
\text { Peritoneal } \\
\text { biopsy }\end{array}$ & $\begin{array}{l}\text { Peritoneal } \\
\text { lavage, } \\
\text { Peritoneal } \\
\text { biopsy, } \\
\text { Histology }\end{array}$ \\
\hline $\mathrm{C}$ & 8 & & & & $\begin{array}{c}\text { Adhesion } \\
\text { evaluation, } \\
\text { Digital } \\
\text { photography }\end{array}$ \\
\hline D & 8 & & & & $\begin{array}{c}\text { Adhesion } \\
\text { evaluation, } \\
\text { Digital } \\
\text { photography }\end{array}$ \\
\hline
\end{tabular}


scar on the lateral abdominal wall area and surrounding tissue was excised. The area covered by adhesions was stained using tissue color and the whole excised operative area was defined and marked. Thereafter, the area was digitally photographed and transferred to a computer.

Straight after that an evaluation for euthanasia was made, all in accordance to AVMA Guidelines on Euthanasia 2007 [13] where, still during anesthesia, the animals received an intravenous over dose of potassium chloride.

\subsection{Evaluations}

The quality of the peritoneal adhesion was scored according to Lang et al. [14]. After that the digital photographs of the defined operated and colour marked adhesive areas were calculated using a CAD program (AuoCad 2011 Autodesk AB, Göteborg, Sweden). Ratios (percent) were calculated between the adhesion area and the total incised abdominal area and analyzed for differences. Histology slides were evaluated. Fibrosis was scored based on collagen deposition on peritoneum and inflammation was scored based on lymphocytes and macrophages [15] (see Table 2). Histology evaluation was performed separately by two examiners and in a blinded fashion.

Table 2. Fibrosis and inflammation score.

\begin{tabular}{cc}
\hline Score & Fibrosis/Inflammation \\
\hline 0 & None \\
1 & Mild \\
2 & Moderate \\
3 & Severe \\
\hline
\end{tabular}

Evaluation score of histology fibrosis (peritoneal collagen deposition) and inflammation (amount of macrophages and lymphocytes according to Hooker et al. [13]).

\subsection{Biochemical Assays}

Determination of active proteins in peritoneal fluid was carried out using commercially IL-6 (R \& D Systems ${ }^{\mathrm{TM}}$, Abingdon, UK), TGF-b1 (Promega Biotech AB ${ }^{\mathrm{TM}}$ Nacka, Sweden). The active proteins were normalized to total protein (Bio-Rad Laboratories AB Malmö, Sweden).

The tPa/PAI-1 complex was analyzed in supernatant obtained from homogenized peritoneal biopsies using ELISA (t-Pa/PAI-1 Complex ELISA, Haemochrom Diagnostica AB, Mölndal, Sweden,) according to the manufacturer's instructions. Results were also normalized to total protein concentration.

\subsection{Statistics}

In order to see the distribution of the values in the figures, all results were given in median.

The Mann Whitney U Test was used to analyze dif- ferences in adhesion score from digital photos and histology slides (inflammation and fibrosis).

Kruskal Wallis test was used to determine statistic differences in active protein levels of peritoneal fluid and peritoneal biopsy between the control and experiment group. Statistic differences were set to $\mathrm{p}<0.05$ (SPSS v17.0 SPSS Inc., Chicago, Illinois, USA).

\section{RESULTS}

After the text edit has been completed, the paper is ready for the template. Duplicate the template file by using the save as command, and use the naming convention prescribed by your journal for the name of your paper. In this newly created file, highlight all of the contents and import your prepared text file. You are now ready to style your paper.

\subsection{Adhesions}

A significant difference in abdominal adhesions could be seen between the experimental and control (group $C$ and D) groups, $\mathrm{p}<0.005$ (Figure 1). In the control group, $100 \%(8 / 8)$ of the rabbits had severe adhesions vs. only $9 \%(1 / 8)$ in the PLPG group. In the PLPG group 63\% (5/8) had no adhesions and 25\% (2/8) had flimsy adhesions.

The digital photo (Figure 2) showed that the peritoneal surface was smooth and similar to the rest of the non-traumatized peritoneal surface.

\subsection{Inflammation and Fibrosis}

Ten days after surgery, hematoxylin/eosin staining for inflammatory cells on submesothelial area did not show any difference after 10 days comparing control and experimental groups as measured according to Table 2

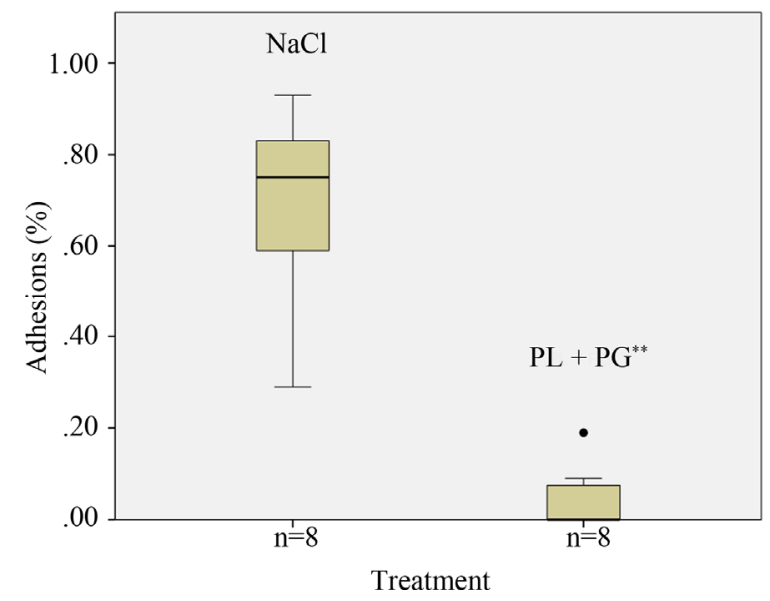

Figure 1. Results of adhesion reduction in animals receiving PLPG. Adhesions in percent of traumatized area in animals treated with saline and PLPG; ${ }^{* *}$ Significant reduction; $\mathrm{p}<0.005$. 
(Figure 3). An increase in collagen deposition on peritoneum was seen on histology (Massons-Trichrome) in the control group compared to the experimental group $\mathrm{p}$ $<0.05$ (Figure 4).

\subsection{Peritoneal Fluid Measurement}

There was no difference between treated animals and controls regarding $\mathrm{tPa} / \mathrm{PAI}-1$ complex in peritoneal biopsies.

IL-6 in peritoneal fluid was slightly, although not significant, decreased in experimental animals compared to the control group on day 4 postoperatively $(\mathrm{p}=0.20)$.

The amount of active TGFb1 was slightly decreased on day 4 and 10 in the peritoneal fluid of the experimental group; however, the difference was not statisticcally significant ( $p=0.20$ and 0.13 , respectively). All animals fared well without signs of any toxic symptoms during the experiments and there was no weight loss recorded.

\section{DISCUSSION}

The present study is the first one, to our knowledge, that has been done on rabbits with $\alpha$-poly-L-lysine and polyL-glutamate (PLPG) as an abdominal adhesion preven-
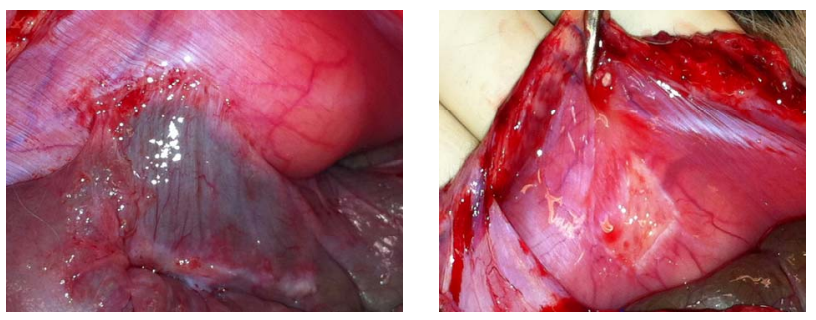

Figure 2. Photographies of treatment effect after 10 days.

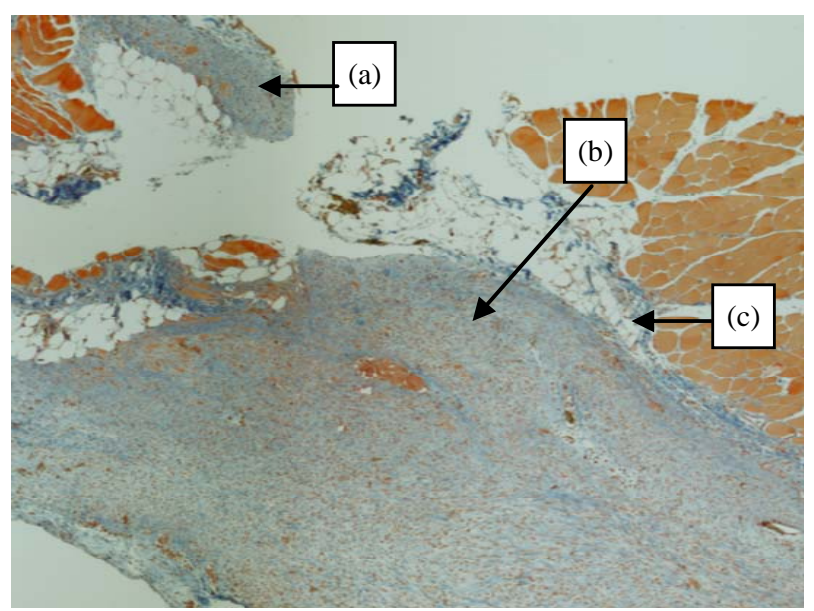

Figure 3. Histology (hematoxylin/eosine) specimen after 10 days. Differences in the fibrosis reaction between (a) (peritoneum treated with PLPG) and (b) (adhesions formation not treated with PLPG) after surgery. (c) is the submesothelial area.

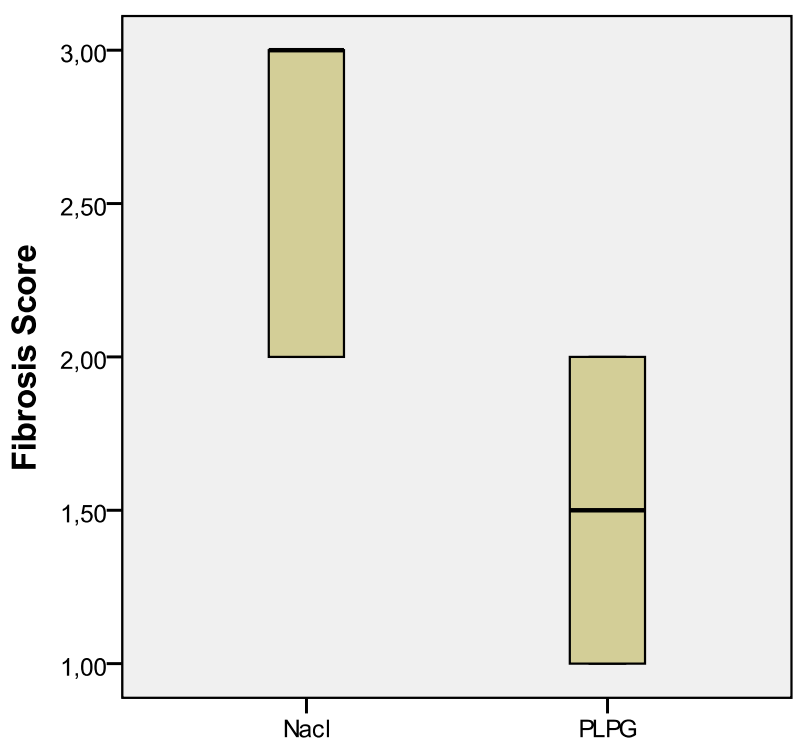

Figure 4. Differences in collagen deposition on the peritoneum in the saline group as compared to the PLPG group; $\mathrm{p}<0.05$.

tive agent, as well as the first study to show effective adhesion control using administration by spraying polypeptides instead of intra-abdominal installation. We have in previous experimental studies shown a strong postsurgical intra-abdominal, anti-adhesive effect of differently charged polypeptides [16]. The best anti-adhesive effect was achieved by combining the two oppositely charged polypeptides $\alpha$-poly-L-lysine and poly-L-glutamate creating a matrix which serves as a mechanical barrier to prevent adhesion formation [12]. Other combinations of polypeptides have also shown significant reduction in abdominal adhesions though not to the same degree [17]. The PLPG complex has proven to be a biodegradable and non-toxic anti-adhesive agent that accumulates on injured peritoneum and in conjunction with its anti-adhesive effect also decreases parenchymal bleeding. Furthermore, the PLPG complex has no negative effect on bowel anastomoses but rather seem to assist in anastomotic healing [18-20]. The anti adhesive effect of the PLPG complex has been evaluated up to 5 months in rats with the same promising results [18].

The result from the present study shows a significant reduction in peritoneal adhesions, both on histological examination (collagen staining) and the amount of peritoneal adhesions. Adhesions in the control group appeared as rough pale bands on the peritoneum whereas the scarce adhesions in the PLPG group only showed a slightly pale discoloration beneath, an otherwise smooth peritoneum (Figure 2). By this finding, in addition to the smooth cecal serosal surface in treated animals, we concluded that the pale color emanated from small amounts (much thinner collagen surface than the control group) of collagen seen on histology (Figure 3(a)) indicating that 
the PLPG matrix seals off the damaged peritoneal surface. This sealing could contribute to a smaller amount of inflammatory exudate than normally seen in the damaged peritoneum [21]. An indirect sign of this could be the decreased amount of collagen deposition.

These anti-adhesion results are consistent and correspond with previous studies, although not tested in rabbits. In the prior studies PLPG was used as an abdominal instillation in the dose of $40 \mathrm{mg} / \mathrm{kg}$ (mice) and the anti-adhesive effect remained at $1.6 \mathrm{mg} / \mathrm{kg}$ [22]. In this study, due to the size of the animals, we were able to treat them locally using spray administration by spraying in the dose of $2.5 \mathrm{mg} / \mathrm{kg}$ PLPG. Still, a very good antiadhesive effect was reproduced indicating that local administration of a much smaller dose is possible. For forthcoming human experiments this is crucial. No toxic effects were noted during this experimental study in rabbits.

The normal peritoneal process of healing after trauma and the process of abdominal adhesion formation both involve the mesothelial and submesothelial areas [23-26]. The process of healing, as well as formation of adhesions, is among others mediated by inflammatory cells, mesenchymal cells [27], progenitor cells, tPa, PAI-1, active TGFb1 and inflammatory cytokines (IL1-6). Adhesion formation is a dynamic process where stable adhesions are formed within two weeks. It has previously been shown in rats that active tPa in peritoneal fluid significantly increases $24 \mathrm{~h}$ after peritoneal trauma and thereafter returns to normal levels. On the other hand, tPA activity in peritoneal biopsies has been shown to increase up to $72 \mathrm{~h}$ after surgical trauma to the peritoneum. PAI-1 in peritoneal fluid has been shown to increase from $4 \mathrm{~h}$ up to $72 \mathrm{~h}$ after peritoneal surgical trauma [28]. Active TGFb1 in peritoneal fluid was previously shown to gradually increase in peritoneal fluid over a period from 1 to 4 days and thereafter declined, but still remained significantly elevated compared to controls after 7 days [29]. IL-6 has shown to be involved in the process of abdominal adhesion formation. Previous studies have shown IL-6 to be elevated in peritoneal fluid during surgical trauma and antibodies against IL-6 have been reported to decrease abdominal adhesions [30]. The active proteins (mentioned above) are secreted by various cells (mesothelial cells, macrophages, neutrophils, endothelial cells from capillaries in the submesothelial space and fibroblasts) that all plays an important role in the peritoneal adhesion formation and degradation [31-35].

In peritoneal fluid there was no difference in $\mathrm{tPa} /$ PAI-1 complex between the control and experiment group before wound inflicting surgery. Individual measured times did not differ statistically measured between the groups. Active TGFb1 and IL-6 showed no differences between the groups.

These results for active proteins in peritoneal fluid could be due to many factors. One of them being that
PLPG has an effect on peritoneal injury that decreases the inflammatory exudate from the injured site (sealing) thus decreasing topical collagen deposition, though without interfering with the submesothelial space. A previous paper showed that the FITC labeled PLPG complex was incorporated in the intestinal wall without interfering with its function [16]. We speculated that this also might be the case for the submesothelial space.

The amounts of inflammatory cells were equal in both groups based on evaluating the histology slides. The inflammatory cells were concentrated in the submesothelial space, which further strengthens our hypothesis that the submesothelial process is not affected by the PLPG complex. We have previously shown that the function of peritoneal macrophages is not impaired when using the PLPG-concept, which is one of the evidences that the PLPG bio absorbable complex does not conflict the crucial steps in the normal peritoneal healing process [12].

\section{CONCLUSION}

This pilot study of local administration and mechanisms behind the anti-adhesive PLPG effect shows that PLPG significantly diminishes the amount of abdominal adhesions in rabbits using administration by spraying in a low dose. The effect seems to be topical on the peritoneum and without influencing the submesothelial space. No effects were noted in the peritoneal fluid on crucial and central parameters involved in adhesion formation.

\section{ACKNOWLEDGEMENTS}

This study was performed in parts due to grants from Åke Wiberg Foundation, Magnus Bergvall Foundation, Zoegas foundation and Regional hospital funds.

\section{REFERENCES}

[1] Tingstedt, B., Andersson, E., Isaksson, K. and Andersson, R. (2008) Clinical impact of abdominal adhesions: What is the magnitude of the problem? Scandinavian Journal of Gastroenterology, 43, 255-261. doi:10.1080/00365520701708626

[2] Tingstedt, B., Isaksson, J. and Andersson, R. (2007) Long-term follow-up and cost analysis following surgery for small bowel obstruction caused by intra-abdominal adhesions. British Journal of Surgery, 94, 743-748. doi:10.1002/bjs.5634

[3] Sulaiman, H., Dawson, L., Laurent, G.J., Bellingan, G.J. and Herrick, S.E. (2002) Role of plasminogen activators in peritoneal adhesion formation. Biochemical Society Transactions, 30, 126-131. doi:10.1042/BST0300126

[4] Liakakos, T., Thomakos, N., Fine, P.M., Dervenis, C. and Young, R.L. (2001) Peritoneal adhesions: Etiology, pathophysiology, and clinical significance. Recent advances in prevention and management. Digestive Surgery, 18, 
260-273. doi:10.1159/000050149

[5] Chegini, N. (2022) Peritoneal molecular environment, adhesion formation and clinical implication. Frontiers in Bioscience, 7, 91-115. doi:10.2741/chegini

[6] Di Filippo, C., Falsetto, A., De Pascale, V., Tufariello, E., De Lucia, D. and Rossi, F. (2006) Plasma levels of t-PA and PAI-1 correlate with the formation of experimental post-surgical peritoneal adhesions. Mediators of Inflammation, 4, 13901.

[7] Thompson, J. (1998) Pathogenesis and prevention of adhesion formation. Digestive Surgery, 15, 153-157. doi:10.1159/000018610

[8] Prushik, S.G., Stucchi, A.F., Matteotti, R., Aarons, C.B., Reed, K.L. and Gower, A.C. (2010) Open adhesiolysis is more effective in reducing adhesion reformation than laparoscopic adhesiolysis in an experimental model. British Journal of Surgery, 97, 420-427. doi:10.1002/bjs.6899

[9] Neudecker, J., Junghans, T., Raue, W., Ziemer, S. and Schwenk, W. (2005) Fibrinolytic capacity in peritoneal fluid after laparoscopic and conventional colorectal resection: Data from a randomized controlled trial. Langenbecks Archives of Surgery, 390, 523-527. doi:10.1007/s00423-005-0582-3

[10] Lucas, P.A., Warejcka, D.J., Young, H.E. and Lee, B.Y. (1996) Formation of abdominal adhesions is inhibited by antibodies to transforming growth factor-beta1. Journal of Surgical Research, 65, 135-138. doi:10.1006/jsre.1996.0355

[11] Cheong, Y.C., Laird, S.M., Shelton, J.B., Ledger, W.L., Li, T.C. and Cooke, I.D. (2002) The correlation of adhesions and peritoneal fluid cytokine concentrations: A pilot study. Human Reproduction, 17, 1039-1045. doi:10.1093/humrep/17.4.1039

[12] Nehez, L., Vodros, D., Axelsson, J., Tingstedt, B., Lindman, B. and Andersson, R. (2005) Prevention of postoperative peritoneal adhesions: Effects of lysozyme, polylysine and polyglutamate versus hyaluronic acid. Scandinavian Journal of Gastroenterology, 40, 11181123. doi:10.1080/00365520510023332

[13] http://www.avma.org/issues/animal_welfare/euthanasia.p df

[14] Lang, R.A., Weisgerber, C., Gruntzig, P.M., Weis, C., Odermatt, E.K. and Kirschner, M.H. (2009) Polyvinyl alcohol gel prevents adhesion re-formation after adhesiolysis in a rabbit model. Journal of Surgical Research, 153, 12-16. doi:10.1016/j.jss.2008.04.018

[15] Hooker, G.D., Taylor, B.M. and Driman, D.K. (1999) Prevention of adhesion formation with use of sodium hyaluronate-based bioresorbable membrane in a rat model of ventral hernia repair with polypropylene mesh-A randomized, controlled study. Surgery, 125, 211-216. doi:10.1016/S0039-6060(99)70267-9

[16] Nehez, L., Tingstedt, B., Vodros, D., Axelsson, J., Lindman, B. and Andersson, R. (2006) Novel treatment in peritoneal adhesion prevention: protection by polypeptides. Scandinavian Journal of Gastroenterology, 41, 1110-1107. doi:10.1080/00365520600554550
[17] Nehez, L., Tingstedt, B., Axelsson, J. and Andersson, R. (2007) Differently charged polypeptides in the prevention of post-surgical peritoneal adhesions. Scandinavian Journal of Gastroenterology, 42, 519-523. doi:10.1080/00365520600988204

[18] Tingstedt, B., Nehez, L., Axelsson, J., Lindman, B. and Andersson, R. (2006) Increasing anastomosis safety and preventing abdominal adhesion formation by the use of polypeptides in the rat. International Journal of Colorectal Disease, 21, 566-572. doi:10.1007/s00384-005-0053-x

[19] Tingstedt, B., Nehez, L., Lindman, B. and Andersson, R. (2007) Effect of bioactive polypeptides on leaking large bowel anastomosis and intestines in the rat. Journal of Investigative Surgery, 20, 229-235. doi:10.1080/08941930701481288

[20] Tingstedt, B., Nehez, L., Lindman, B. and Andersson, R. (2007) Efficacy of bioactive polypeptides on bleeding and intra-abdominal adhesions. European Surgical Research, 39, 35-40. doi:10.1159/000098438

[21] ArRajab, A., Mileski, W., Sentementes, J.T., Sikes, P., Harris, R.B. and Dawidson, I.J. (1996) The role of neutrophils in peritoneal adhesion formation. Journal of Surgical Research, 61, 143-146. doi:10.1006/jsre.1996.0095

[22] Isaksson, K., Akerberg, D., Andersson, R. and Tingstedt, B. (2010) Toxicity and dose response of intra-abdominally administered poly-L-alpha-lysine and poly-L-glutamate for postoperative adhesion protection. European Surgical Research, 44, 17-22. doi:10.1159/000258654

[23] Renvall, S., Lehto, M. and Penttinen, R. (1987) Development of peritoneal fibrosis occurs under the mesothelial cell layer. Journal of Surgical Research, 43, 407-412. doi:10.1016/0022-4804(87)90098-9

[24] Miyamoto, T., Tamura, M., Kabashima, N., Serino, R., Shibata, T. and Furuno, Y. (2010) An integrin-activating peptide, PHSRN, ameliorates inhibitory effects of conventional peritoneal dialysis fluids on peritoneal wound healing. Nephrology Dialysis Transplantation, 25, 11091119. doi:10.1093/ndt/gfp601

[25] van der Wal, J.B. and Jeekel, J. (2007) Biology of the peritoneum in normal homeostasis and after surgical trauma. Colorectal Disease Journal, 9, 9-13. doi:10.1111/j.1463-1318.2007.01345.X

[26] Imudia, A.N., Kumar, S., Saed, G.M. and Diamond, M.P. (2008) Pathogenesis of Intra-abdominal and pelvic adhesion development. Seminars in Reproductive Medicine, 26, 289-297. doi:10.1055/s-0028-1082387

[27] Mutsaers, S.E. (2008) The mesothelial cell. The International Journal of Biochemistry \& Cell Biology, 36, 9-16. doi:10.1016/S1357-2725(03)00242-5

[28] Hellebrekers, B.W., Trimbos-Kemper, G.C., Bakkum, E.A., Trimbos, J.B., Declerck, P.J. and Kooistra, T. (2000) Short-term effect of surgical trauma on rat peritoneal fibrinolytic activity and its role in adhesion formation. Journal of Thrombosis and Haemostasis, 84, 876-881.

[29] Ghellai, A.M., Stucchi, A.F., Chegini, N., Ma, C., Andry, C.D. and Kaseta, J.M. (2004) Role of transforming growth factor beta-1 in peritonitis-induced adhesions. 
Journal of Gastrointestinal Surgery, 4, 316-323. doi:10.1016/S1091-255X(00)80082-7

[30] Saba, A.A., Kaidi, A.A., Godziachvili, V., Dombi, G.W., Dawe, E.J. and Libcke, J.H. (1996) Effects of interleukin-6 and its neutralizing antibodies on peritoneal adhesion formation and wound healing. The American Journal of Surgery, 62, 569-572.

[31] Rougier, J.P., Guia, S., Hagege, J., Nguyen, G. and Ronco, P.M. (1998) PAI-1 secretion and matrix deposition in human peritoneal mesothelial cell cultures: Transcriptional regulation by TGF-beta 1 . Kidney International, 54, 87-98. doi:10.1046/j.1523-1755.1998.00955.X

[32] Topley, N., Jorres, A., Luttmann, W., Petersen, M.M., Lang, M.J. and Thierauch, K.H. (1993) Human peritoneal mesothelial cells synthesize interleukin-6: Induction by IL-1 beta and TNF alpha. Kidney International, 43, 226-233. doi:10.1038/ki.1993.36
[33] van Hinsbergh, V.W., Kooistra, T., Scheffer, M.A., Hajo van Bockel, J. and van Muijen, G.N. (1990) Characterization and fibrinolytic properties of human omental tissue mesothelial cells. Comparison with endothelial cells. Blood, 75, 1490-1497.

[34] Freyria, A.M., Paul, J., Belleville, J., Broyer, P. and Eloy, R. (1991) Rat peritoneal macrophage procoagulant and fibrinolytic activities. An expression of the local inflammatory response. Comparative Biochemistry and Physiology, 99, 517-524.

[35] Ivarsson, M.L., Holmdahl, L., Falk, P., Molne, J. and Risberg, B. (1998) Characterization and fibrinolytic properties of mesothelial cells isolated from peritoneal lavage. Scandinavian Journal of Clinical \& Laboratory Investigation, 58, 195-203. doi:10.1080/00365519850186580 